\title{
Erratum to: Kufi Lari: The Hybrid of Khat Kufi to Uphold the Malays' Identity in Digital Art Application
}

\author{
Mohd Amin Mohd Noh, Mohd Fauzi Harun, \\ Nik Narimah Nik Abdullah, Nor Fariza Baharuddin \\ and Zahara Ramli
}

Erratum to:

Chapter "Kufi Lari: The Hybrid of Khat Kufi to Uphold the Malays' Identity in Digital Art Application"

in: S.Z. Abidin et al. (eds.), Proceedings

of the 2nd International Colloquium of Art

and Design Education Research (i-CADER 2015),

DOI 10.1007/978-981-10-0237-3_60

The original version of this chapter was inadvertently published with incorrect author groups and it has been updated with the correct author names as "Mohd Amin Mohd Noh, Mohd Fauzi Harun, Nik Narimah Nik Abdullah, Nor Fariza Baharuddin, and Zahara Ramli."

The updated original online version for this chapter can be found at 10.1007/978-981-10-0237-3_60

M.A. Mohd Noh (ه) · M.F. Harun · N.N. Nik Abdullah · N.F. Baharuddin · Z. Ramli Community of Research for Humanities, Design and Creativity, Universiti Teknologi MARA, 40450 Shah Alam, Malaysia

e-mail: fanzine11@gmail.com

N.N. Nik Abdullah

e-mail: nnarimah@yahoo.com 